\title{
O INCA PANO: MITO, HISTÓRIA E MODELOS ETNOLÓGICOS
}

Oscar Calavia Sáez

Quatorze anos atrás, o J ournal of Latin American Lore publicou um extenso artigo de Donald Lathrap, Angelika Gebhart-Sayer e Ann M ester (1985) sobre a relação de grupos pano da Alta Amazônia com uma aristocracia quechua.

Em meio a uma enciclopédica e ousada reconstrução do processo histórico pan-pano, a peça de convicção do artigo era uma série de relatos protagonizados pelo Inca, obtida por Gebhart-Sayer entre os índios do Ucayali. Séculos antes de sua instalação como senhores nos Andes, alguns grupos quechua teriam estabelecido seu reino na selva, e a tradição oral conservaria preciosos detalhes daquela época.

As tradições referentes ao Inca entre índios da Alta Amazônia não eram desconhecidas antes de 1985. Longe de se limitarem aos grupos fluviais do Ucayali (afinal, relativamente próximos aos Andes), estendem-se também a grupos mais orientais, especialmente os Kaxinawá. M as até então o assunto não passava de uma vaga curiosidade mitológica. A interpretação "imediatista" de uma tradição oral, que dá o tom do artigo, encontrou muita resistência entre antropólogos e historiadores-arqueólogos, e obrigou a uma definição de posições. Entre resenhas críticas, respostas e redargüições, formou-se um corpus importante de literatura sobre o “Inca Pano" 1. Um resumo, uma análise ou uma continuação da polêmica demandariam demasiado espaço; bastará indicar as duas linhas principais de crítica.

A primeira postula que qualquer "memória" do Inca pode ser reduzida a conteúdos atuais. Esses relatos sobre um Inca ambíguo - um herói cultural, origem de riquezas, mas também um opressor mesquinho - sugerem uma reflexão sobre o branco, e sobre os ciclos de aliança e guerra que com ele mantiveram durante séculos os índios do Ucayali². Incas de batina, ou fornecedores de motores, como alguns que apareciam no material shipibo, constituíam apoios convincentes para a suspeita de que dados e personagens históricos não eram mais do que peças na bricolagem mitológica. 
Outra linha crítica - compatível com a primeira - indicava fontes alternativas para a figura do Inca, fazendo desnecessária a tese da memória. O fantasma incaico, como sabemos, tem sido uma constante no mundo andino e circum-andino. Os agentes do império espanhol que incorporaram o modo "incaico" de entender a selva, os missionários empenhados em difundir o quechua como língua franca, os líderes de movimentos messiânicos que agiram como descendentes do Inca e os arautos de algumas variedades de nacionalismos indianistas têm atual izado constantemente, desde o século XVI até o presente, um mito Inca3. A tese de Lathrap reivindica a consciência histórica dos índios amazônicos, mas de modo singularmente coerente com o paradigma primitivista: ela se manifestaria na lembrança passiva de uma origem cultural remota. M elhor serviço se faria à etnohistória indígena demostrando a capacidade dos "historiadores" indígenas de adotar e adaptar informações mais recentes. Poucos autores negariam hoje a intensidade e a antiguidade da comunicação entre a cordilheira e a floresta. Os documentos históricos são taxativos, abundantes e relativamente bem conhecidos: só um certo bias evolucionista tendia a fazer das duas regiões pólos opostos na tipologia das culturas americanas.

Em princípio, as duas críticas à tese de Lathrap, Gebhart-Sayer e M ester são compatíveis com o reconhecimento de um contato primitivo entre elites andinas e povos amazônicos. Foram formuladas por especialistas interessados na etnohistória, isto é, abertos à legitimidade da memória indígena. Se tirarmos de cena o fundamentalismo interpretativo de Gebhart-Sayer, a polêmica encolhe para uma discussão de detalhes. Como um todo, foi útil para expor ou questionar esse evolucionismo residual embutido em binômios analíticos como terras altas/baixas e meio fluvial/interfluvial ou certas acepções substancialistas da história e da identidade étnica; mas algumas de suas conseqüências não foram exploradas. As críticas, no seu conjunto, optaram pela dissolução: apostaram na capacidade da cultura de digerir dados históricos, ou em uma enxurrada de informações "incaicas" que tiraria do Inca Pano qualquer relevância específica. A proposta de G ebhart-Sayer mantém, apesar de tudo, o atrativo de reconhecer um elemento histórico irredutível - al go que as análises semânticas conseguem eludir, mas não integrar: por que, afinal, o Inca sempre? Por que não simplesmente o mito do Branco que encontramos em tantos outros lugares?

Examinarei esta questão comparando repertórios mitológicos recoIhidos em uma área relativamente reduzida, com três protagonistas: os Shipibo, que se estendem pelo Ucayali e o Madre de Dios e constituem 
uma das etnias mais numerosas da A mazônia - com uma população avaliada em torno de 23.000 indivíduos - , ocupam o centro da questão incaica. Os Kaxinawá têm suas aldeias no curso al to de vários rios do sistema J uruá-Purus, mas os dados oferecidos aqui procedem, em sua maior parte, de grupos situados no A Ito Purus. Eles fazem freqüentes referências ao Inca na sua mitologia, embora em lugar menos central que no caso shipibo. O s Yaminawa, enfim, não têm relatos sobre o Inca4, mas esta é uma falta que pode ser significativa. Com efeito, as diversas críticas à "memória do Inca" explicariam coerentemente a presença desse personagem na tradição oral de alguns povos, mas não sua ausência sistemática na de outros que compartilham com os primeiros o mesmo espaço geográfico e lingüístico, o mesmo histórico de relação com os brancos, enfim a mesma mitologia5. Outros grupos pano, ou grupos arawak vizinhos, poderiam se integrar em uma versão ampliada deste texto. M as Shipibo, Kaxinawá e Yaminawa formam um conjunto coerente desde muitos pontos de vista, dentre eles o da mitologia, consideravelmente homogênea. A presença ou ausência do Inca no corpus mítico marca de fato um contraste essencial entre eles, e ganha relevância particular na comparação entre Yaminawa e Kaxinawá, que constituirá o eixo da minha argumentação6.

\section{Inca na mitologia pano}

Começarei oferecendo um repertório amplo dos mitos que - embora não exaustivo - deixe clara ao menos a variedade interna do personagem.

Comecemos pelo Inca do Ucayali. O relato de Bardales Rodríguez (1979) é especial mente valioso apesar ou por causa da sua vontade de sistema7. Resume uma pluralidade de Incas - três - vinculados com diversos grupos pano e a distintos locais. Do mais simples ao mais complexo (invertendo assim a ordem de exposição de Bardales, que vai do Inca ruim ao bom Inca), temos o Chane Inca, ou Inca Pássaro, dos Conibo de Cumaria; o Cheshe Inca, ou Inca Negro, dos Shipibo de Santa Rosa; e o Yoaxico Inca, o Inca Sovina, dos Shetebo de Tsoaya.

O Chane Inca é um herói cultural que, junto com sua mulher, ensina as artes - a pintura, o tecido, a cerâmica - aos Conibo. Ele conhecia todos os lugares e viajava longe com suas gentes à procura de materiais. Depois, desapareceu atrás do rio Cumaria. Só não disse aos Conibo o que fazer com o ouro, "porque sabia que os estrangeiros viriam a esta comarca" (1979:53).

O Inca Negro dos Shipibo é apresentado também como um grande doador, mas as artes que ele outorga são de outra natureza: bom caçador 
e bom construtor de casas, el e ensina os índios a preparar caiçuma, i.e., a celebrar festas; as pescarias que ele ordena para estas festas produzem uma prodigiosa quantidade de peixe e tartaruga. Esse provedor decide um belo dia ir embora, mas para consolar seus seguidores promete trazer para el es uma planta (rau, remédio); quando o Inca está ausente procurando esta planta, eles se embebedam e matam uma velha. Quando o Inca volta, ordena aos matadores que comam o cadáver - "o que se mata é para comer" (1979:50) - e os envia a morar nos rios Pachitea e Aguaytía, passando a ser chamados joni piai ("comem gente"); deles descendem os Cashibo. Outros são banhados pelo Inca com a planta, e enviados a morar em Cumancay e no rio Macanari; são chamados de jishtimabo, "os invisíveis". Depois, ele mesmo vai rio acima, levando alguns filhos de seu povo, cujos familiares o seguem por isso; seguem seu rastro mas não conseguem alcançá-lo, e desistem ao chegar a "um grande sal to do rio". Voltam assim a Santa Rosa, e deles descendem os atuais Shipibo.

Quanto ao Inca Sovina, o Yoaxico Inca dos Shetebo, a narração de Bardales é uma verdadeira saga de cinco relatos, dos quais os quatro primeiros consistem em episódios protagonizados por um mesmo personagem, sempre caracterizado pelo seu comportamento mesquinho. No primeiro, narra-se a morte do Sovina em mãos de animais: o sangue do Sovina tinge diversas aves. No segundo, especifica-se a sovinice do personagem: dono de todas as plantas cultivadas, oferece aos homens o produto de suas roças, mas cada planta tem um animal peçonhento como guardião: a macaxera tem tocandira; a banana, vespas; o ananás, cobras. 0 Sovina é também dono do fogo, que sonega aos homens até que Sheta (Papagaio) consegue roubar uma brasa com seu bico. No terceiro e quarto relatos, o Inca exercita sua maldade com seu genro: tenta queimá-lo pondo fogo na derrubada quando ele está trabalhando no meio. O genro consegue escapar, mas duas calabaças que ele tinha estouram; o Inca, ouvindo, pensa que se trata da cabeça e da barriga do genro, e se surpreende quando o vê voltar são e salvo para casa. Em outra ocasião (quarto relato) manda o genro com seus soldados pescar com timbó. Quando todos estão no meio da lagoa, o Inca chega e grita que o J ascatash e os Manshanteo (duas aves aquáticas - Toyuyo e M anchaco) estão acabando com os peixes. Nesse momento, o genro e os soldados convertem-se nas ditas aves.

O quinto relato, muito mais complexo, é explicitamente atribuído a um Inca "que não era o Sovina", e é praticamente idêntico ao mito do Dilúvio da versão de Roe (1982); o presente resumo refere-se a ambas as versões: 
Esse relato compõe-se de diversos episódios: o mau trato - ou o assassinato - de um menino (que resulta ser o filho do Inca) por um índio que inveja sua sorte na pesca; o resgate do menino por um outro índio, e o anúncio de um dilúvio punitivo do qual apenas o bom samaritano se salvará, junto com sua família, subindo em um pé de jenipapo; o dilúvio, durante e depois do qual o Noé Pano é milagrosamente provido de alimento; a retirada das águas, e a conversão da mulher e filho do herói em um cupinzeiro e um pássaro; a escolha errada do herói, que, vendo aparecer duas jovens em uma canoa, agarra a serva e despreza a filha do Inca, que este Ihe destinava como esposa; e finalmente a perda da imortalidade humana - de novo por culpa do torpe herói que, contra os conselhos de sua mulher, espia o parto desta.

Os Incas de Bardales - que dão uma idéia cabal do tipo de tradição em que Gebhart-Sayer se baseia - formam um contínuo que vai da extrema sovinice do Inca Shetebo (a negação dos produtos de subsistência) à extrema generosidade do Inca Conibo (o dom das artes suntuárias que constituem o signo distintivo da etnia). O Inca Negro, e com ele o grupo shipibo, ocupa um espaço intermediário. Seus dons são os de um grande anfitrião: bebida, pesca, casa, festa... mas vêm sempre acompanhados de árduas conseqüências: bebedeiras, homicídios, canibalismo. Todo o relato conduz à dispersão étnica: as gentes do Inca N egro dividem-se em três (de novo três) grupos.

O trinitarismo do autor força-o a acomodar no capítulo do Inca Sovina um outro Inca reconhecidamente diferente: aquele Inca implícito representado por seu filho e sua filha - do relato do Dilúvio. A heterogeneidade desse relato é menor se considerarmos que a escol ha matrimonial errada do herói é apresentada como a origem da carência de bens manufaturados.

Voltarei com mais vagar sobre essas narrativas. Por enquanto, é preciso ampliar o inventário.

Não é menor a complexidade dos Incas kaxinawá. Na coletânea de Capistrano de A breu (1941:linhas 4996-5142) o Ĩká é protagonista de três episódios. No primeiro, İká, caracterizado como um grande diabo (mawa iuxibó), convida os Kaxinawá a balançar-se enquanto ele canta suas cantigas; os que não se balançam, ele mata e come. Inquietos com essas brincadeiras, os Kaxinawá decidem ir embora para longe dele. Em outro momento, Ĩká convida a aranha a morar junto com ele e sua mulher, e the dá os frascos do frio e da noite. Finalmente, assumindo algumas feições do Sovina, nega ao Urubu, que está com muito frio, o Sol que ele guarda em outro frasco. Não se trata dessa vez de uma sovinice individual: em 
conversas com Ĩká, o gavião pega-macaco (nawa tete) recomenda-Ihe não compartilhar o Sol com gentinha. O Urubu, porém, sabe que o Sol está guardado no seu frasco, e consegue roubá-lo.

O Pe. Tastevin (1925:23-26) refere-se a dois tipos de narrativa sobre o Inca. De um lado, as protagonizadas pelo Inca Yauchikunawa, o mesmo Sovina que já conhecemos pelo relato de Bardales e que aparecerá constantemente nestas páginas. Dono do fogo, da mandioca, do milho e de outros bens que se recusa a compartilhar com os humanos, esse Inca é vítima de sucessivos roubos por diversos animais. (Lembremos que na versão ucayalina o Sovina é trucidado e a seguir espoliado.)

De outro lado, o Inca aparece também como o membro bobo de um par de heróis culturais. Na versão mais rica, o par Inca/Kuma vai criando os elementos da vida quotidiana, mas Inca, estúpido, faz tudo indevidamente, forçando Kuma a tirá-lo de situações inglórias.

Na segunda metade do século, o Inca kaxinawá torna-se um coletivo. Kensinger (1995:259-263) assinala que uma quarta parte das narrativas kaxinawá se refere a ele. A despeito de sua pluralidade e ambigüidade, al guns caracteres se destacam: os Incas moram em belas aldeias, usam roupas longas que escondem seu sexo e possuem excel entes roçados. São, no entanto, canibais, e embora sejam generosos quanto à sua cultura, instruindo os Kaxinawá em suas artes e cultivos, relutam em entregar suas irmãs em troca das mulheres tomadas destes últimos.

D'A ns (1975) apresenta os Incas do mesmo modo no relato das aventuras de Basabo; em outra narrativa ("La Invención del Parto"), os Incas são parteiros canibais que devoram suas próprias esposas - e as dos Kaxinawá - depois de abri-las para extrair as crianças, até que o rato ensina as mulheres a parir sozinhas.

A mitologia incaica pano é uma obra aberta: os Incas aparecem como afins celestiais em etnografias mais recentes sobre os Kaxinawá (M cCallum 1996; Lagrou 1998); os textos em espanhol inscritos nos quadros de Elias Silva, pintor shipibo moderno, demonstram um interesse pelo tema que provavelmente aproveita as informações sobre o Inca divulgadas pela literatura popular e o sistema escolar peruanos9.

Já afirmei que os relatos sobre o Inca se estendem para al ém dos grupos pano, e ganham relevância especial entre os grupos arawak. O Inca das narrativas piro, por exemplo, tem uma vaga relação com o Kaxinawá, mas situa-se no limite do conjunto. Alvarez (1972:8) refere-se a uma tradição piro segundo a qual os ancestrais ajudaram o Inca a esconder seus tesouros dos espanhóis no monte Ayahuanca. Hassel (1906:67) alude a um relato sobre "Piros caol hos" que ajudaram o Inca na construção da forta- 
leza de Tonquini. Essa eventual colaboração entre os Piro e um soberano andino é a mesma descrita pelas fontes espanholas que tratam do Império de Vilcabamba. Os mitos piro referentes à origem dos seus diversos subgrupos (Alvarez 1972:334-348) são, pel o contrário, variações em torno do tema da sovinice. Assim, os Nachineru são "os famintos", porque o seu rei tinha por costume se alimentar dos brotos das plantas de cultivo. $\mathrm{O}$ rei dos Koshichineru, "os pássaros", consegue finalmente acabar com ele. Outros dois relatos (sobre a origem dos Gagamleru e dos Kuirikuiri) contam as façanhas que outros Piro devem realizar para casar com as filhas de um senhor poderoso ou com as mulheres de uma tribo de "tigres" especialmente ciumentos. As peripécias repetem em boa parte as do esforçado genro do Inca Sovina dos Shetebo. Resulta notável que essa aproximação ao modelo "incaico" - com a presença mesmo desses estranhos "reis" amazônicos - apareça sem um interesse correlato por agrupar todo o complexo em torno de um mesmo protagonista: uma conduta, digamos, inversa à representada pelo Conibo Bardales, empenhado em atribuir a um mesmo personagem feitos muito heterogêneos.

\section{O sovina e os animais}

Uma leitura superficial do acervo mítico Yaminawa coletado durante a minha pesquisa é suficiente para reconhecer os protagonistas, os motivos e as tramas da mitologia "incaica", desde o relato de Yurapibe ("comedor de gente"), até o do menino cujo afogamento gera as chuvas torrenciais, como a morte do filho do Inca no relato shipibo - para dar só dois exemplos.

N esta breve anál ise seria difícil integrar esses elementos, do mesmo modo que muitos outros aspectos dos mitos kaxinawá e shipibo. Mas é possível reconhecer um eixo que une os dois conjuntos de relatos e permite uma comparação sistemática: o do Sovina. Há um conjunto de mitos Yaminawa - que parcialmente se superpõem, sugerindo o encontro de tradições orais de distintos subgrupos nawa - que trata da conquista de uma série de bens, especialmente as plantas cultivadas e o fogo, na luta contra um açambarcador mítico que privava os outros dessas benesses. O personagem corresponde com exatidão ao Inca Sovina dos Shetebo e ao Sovina descrito por Tastevin, e recolhi quatro narrativas referentes a ele: na primeira, é o dono dos bens agrícolas, guardados por animais peçonhentos, que ele só deixa chegar às mãos de outros homens já sapecados ou incapazes de germinar. Os homens juntam-se para matá-lo e se pintar com o seu sangue e as suas vísceras, transformando-se em pássaros. $\mathrm{N}$ a segunda, 
não se trata de um avaro, mas de um feiticeiro perigoso, que mesmo agonizando converte em animais os seus agressores. A segunda e a terceira histórias voltam à sovinice, e narram os truques de que se serviram a andorinha e o papagaio para roubar, respectivamente, o milho e o fogo.

A correspondência é estreita, incluindo as duas alternativas Shetebo/Kaxinawá para o final: a do sovina trucidado e a do sovina roubado.

O Sovina Yaminawa tem duas caras: ele acumula bens inéditos, mas por isso mesmo o seu destino é se converter, espontaneamente ou à força, em esplêndido doador.

É a mesma ambivalência do Inca. A pesar do gradiente de Bardales, é fácil ver que todos os seus Incas são generosos e sovinas ao mesmo tempo. $O$ mais benéfico dos Incas, esse Shane Inca fundador das artes, sonega o domínio do ouro. O único Inca inteiramente desprovido de mesquinharia - o promotor do Dilúvio - é aquele cujos dons o homem não sabe aproveitar. Não é por acaso que o autor o instal ou no capítulo do mais mesquinho dos Incas - aquele cujos bens o homem consegue expropriar mesmo contra a vontade do dono.

Não é estranho que alguns autores queiram identificar esse Inca com os missionários ou com os brancos em geral. Donos de inexplicáveis riquezas, e por isso mesmo tão sovinas quanto generosos - como determinar o limite de ambas as atitudes? -, os relatos sobre o Inca podem muito bem retratá-los: mostram afinal uma evidente preocupação com a origem das mercadorias e de sua distribuição, recorrente nesses mitos de origem do homem branco que encontramos ao longo das A méricas.

\section{Desordem narrativa, desordem social}

À margem do eixo da sovinice, comum à maior parte das narrativas, o Inca parece ser um enunciado vinculado a significados muito diversos. No extremo, digamos, "Inca" não é nada além de um nome, que ao longo deste século tenta se conjugar do melhor modo possível a uma série de temas míticos.

O nome pode ser a base de uma boa organização. A mitologia yaminawa, que reúne a totalidade dos elementos que aparecem nas mitologias vizinhas, carece de personagens estáveis que articulem as diversas narrativas, como o Basabo ou o Romuekoin dos Kaxinawá (ou como o próprio Inca), provavelmente porque a sociedade yaminawa não tem mitógrafos ${ }^{10}$.

Vale a pena fixar esse ponto para controlar uma percepção previsível: aquela que identificaria essa desordem "textual" com a desordem 
que preside outras manifestações da vida yaminawa. Os Yaminawa são aparentemente um bom exemplo da entropia cultural em que o contato com o Branco mergulhou os grupos indígenas. A opinião comum de indigenistas e de outros índios do A cre faz deles ao mesmo tempo desregrados e desagregados - deficitários quanto à cultura e quanto à organização social. Na tese que dedica aos Yaminawa peruanos, Graham Townsley (1988) analisa o esfacel amento de algumas de suas instituições centrais e sua atração pelas ofertas do Branco. Enfim, o confuso conjunto de etnônimos em que aparece envolvida qualquer notícia sobre eles, e mesmo o modo um tanto paradoxal com que definem sua identidade os faz parecer como desafetos à ordem, seja esta cívica ou lógica.

N a minha análise do seu sistema de parentesco (Calavia Sáez 1995, cap. 2) tentei redefinir esse "caos". Longe de se associar a um empobrecimento da organização social, o caos yaminawa dá lugar à convivência de terminologias de parentesco e regras de casamento aparentemente contraditórias. Para limitar este resumo aos aspectos mais marcantes dessa situação, direi que a sociedade yaminawa é conceituada pelos seus membros seja como uma sociedade cognática na qual podem distinguirse metades exogâmicas (isto é, uma variante do modelo dravidiano amplamente distribuído na A mazônia), seja como uma sociedade formada pela soma de "clãs" patrilineares com uma norma complexa de aliança (isto é, um sistema de tipo dakota-iroquês). As duas visões, é claro, não são indistintamente válidas. A primeira predomina quando se considera o conjunto yaminawa desde o grupo doméstico, e é por isso uma visão mais comumente explicitada por mulheres. A segunda predomina nos discursos histórico e político, e é mais facilmente ouvida dos homens ${ }^{11}$.

No meio de ambas as versões acomoda-se ambiguamente $a$ aliança. Os Yaminawa possuem um conjunto completo de termos específicos para designar os aliados em paralel o com uma nomenclatura dravidiana de tipo mais clássico, em que por princípio os termos que designam os parentes incluem também os aliados (assim, por exemplo, o sogro será "tio", e a mulher "prima"). M as eis que essa conotação de aliança no segundo conjunto de termos se mantém de modo paradoxal: em lugar de passar a designar parentes "sem mais", termos como bibiki (que designa o primo/a-esposo/a) sofrem uma espécie de tabu de enunciação, como se o perigo que sempre rodeia a aliança matrimonial continuasse pesando sobre eles. Só nos mitos a palavra bibiki é pronunciada livremente. $\mathrm{O}$ modelo dakota e o dravidiano se desafiam constantemente no dia-a-dia.

A regra de casamento entre os Yaminawa parece estar envolta em reticências muito semelhantes. A única norma clara é de tipo complexo: 
a proibição de casar com parentes próximos, o que inclui praticamente todos aqueles aos quais se aplica um dos termos do sistema "dravidiano", em outras palavras, praticamente a totalidade dos que moram perto. $\mathrm{N}$ ão são raras as acusações de incesto expressas contra indivíduos que teriam casado com suas bibiki. É este precisamente o casamento prescrito em grupos pano vizinhos - incluindo os Yaminawa peruanos - e implícito na própria terminologia: os Yaminawa traduzem bibiki indistintamente como "prima" e "esposa". Tudo pareceria indicar uma reorganização recente da organização social dos Yaminawa no Brasil, que enfatizaria as fronteiras políticas entre as distintas comunidades/etnônimos e, em conseqüência, a tendência a casar com mulheres de outros grupos "nawa" (Bashonawa, Yawanawa etc.), frações dissidentes separadas após conflitos violentos. Os elos genealógicos deixariam de ser reconhecidos quando não acompanhados de co-residência, e isso marcaria a passagem de uma norma de casamento elementar para uma outra complexa.

Em suma, o que uma análise cuidadosa desvenda por trás da desordem yaminawa é uma delicada articulação de ordens virtuais, que pode ser necessária para a viabilidade de uma história difícil. Longe da equação primitivista entre um povo e um sistema de parentesco, teríamos aqui a alternância e o conflito entre vários modos de se organizar conceitualmente uma mesma sociedade. Esse pluralismo implícito, bem entendido, não se limitaria aos Yaminawa: os termos específicos para aliados, embora raras vezes integrados no modelo, encontram-se em quase todas as etnografias pano. Seu escasso rendimento bem pode ser um viés nativo imposto à análise.

O caso kaxinawá oferece, nesse sentido, o melhor termo de contraste. A partir das descrições de Kensinger (1984; 1991), da síntese de Hornborg (1988:167-170) e das análises de Deshayes e Keifenheim (1982) e Keifenheim (1992), os Kaxinawá destacam-se como um caso eminente do que poderíamos chamar sociedade "cristalina". As aldeias kaxinawá, essencialmente endógamas, estariam baseadas na aliança de duas famílias extensas, geradas idealmente por uma troca de irmãs entre os dois shama ibu, que repartiriam as tarefas de chefe e xamã - um dualismo que vai da troca restrita ao campo institucional. Uma terminologia de tipo dravidiano ou kariera excluiria termos específicos de afinidade - MBD equivale a esposa. Os Kaxinawá estariam repartidos em duas metades e, conseqüentemente, em quatro seções - duas por geração - que operam entre si as alianças matrimoniais. Cada seção tem seu nome coletivo, e possui um conjunto de nomes pessoais que se repetem em gerações al ternadas, produzindo uma reedição cíclica da mesma sociedade, e determinando uma soli- 
dariedade intensa entre consanguíneos de gerações alternas portadores do mesmo nome. Um refinado sistema de classificação distingue, na sociedade e na cultura, o que é próprio e o que é al heio, e entre ambos os pólos instala uma alteridade menor, "interna" - "I'autre de dedans" de Deshayes e Keifenheim (1982) —, que serve de anteparo entre ambos.

Para fazer um resumo não especializado, digamos que os Kaxinawá apresentam um sistema dualista sofisticado que une ideologia e função: as metades sociais que organizam ideologicamente o mundo são também as unidades exogâmicas em cuja interação se funda a reprodução social12. Boa parte da etnologia pano gravita em torno desse "modelo kaxinawá" cuja vigência deveria creditar-se ao criterioso conservadorismo do grupo, prudente o bastante para evitar a desordem cultural trazida pelo Branco.

Quanto aos Shipibo, podemos dizer que o parentesco tem jogado um papel muito menos central na literatura a seu respeito. De um lado, estão muito longe da organização "cristalina" dos Kaxinawá. A grande autonomia das unidades domésticas, a reserva no trato entre elas e a tendência a procurar matrimônio com parentes extremamente distantes 13 implicam elos sociais muito frouxos no plano local, e uma sociedade com uma dose de interação bem menor que a dos próprios Yaminawa. No entanto, é interessante notar que nesse caso não parece haver um interesse dos estudiosos em marcar uma desagregação - à qual as terríveis experiências da época da borracha dariam razões de sobra. Isso se deve, sem dúvida, ao fascínio imposto pelas suas artes plásticas: um grafismo altamente sofisticado que os Shipibo compartilham grosso modo com os Kaxinawá e os Piro - mas não, significativamente, com os Yaminawa. A riqueza das formas tem feito, literalmente, esquecer a informalidade da sociedade do Ucayali.

De fato, parece que a arte reforça muito eficientemente os elos de parentesco quando se trata de criar unidades étnicas no Ucayali. O uso e a produção da arte outorgam um sentido de comunidade a uma das etnias mais numerosas da Amazônia: atua no mesmo sentido que a prescrição de casar longe, gerando uma espécie de "nacional idade", atomizada na sua base social e unida em torno de símbolos visuais. Mas a este assunto deveremos voltar mais adiante.

\section{O Inca como afim impossível}

A cabamos de verificar que o parentesco - e mais especialmente certos aspectos da aliança - estabelece uma diferença sistemática entre os grupos que compõem a base etnográfica deste trabal ho. Vamos ver agora 
que essa mesma dimensão pode sistematizar também o contraste entre mitologias com ou sem Inca.

Revisando a mitologia acima resumida, vemos que a sovinice do Inca, embora se exerça em primeiro lugar sobre as plantas cultivadas, tem também suas manifestações nos domínios do cosmos e do parentesco: nega o sol ao Urubu, frustra a reprodução dos Kaxinawá, e também a própria, por causa deste que poderíamos chamar de "canibalismo obstétrico". Não é, afinal, estranho que devore suas próprias mulheres quem não é capaz de dá-las a outros em matrimônio - o incesto e o canibalismo, como sabemos, aparecem com freqüência associados como modos diferentes de "comer a própria carne".

A sovinice fundamental do Inca é a que ele aplica às suas mulheres: consegue unir todos os Incas, sejam mesquinhos ou generosos. A mulher Inca é inacessível, mesmo quando está apaixonada - como no caso de Basabo - ou quando o Inca, em um momento de benevolência, envia sua própria filha para casar com um simples mortal: este escolherá a mulher errada. M esmo quando aparecem como pródigos doadores, inventores das artes e das festas e fundadores de etnias, os Incas não entram na troca matrimonial14. Sua sociedade é estéril: os Kaxinawá imaginam-nos devorando as parturientes ou mesmo os recém-nascidos, e quando nas versões Shipibo aparecem filhos do Inca, é só para serem infelizmente sacrificados ou repudiados pelo homem comum. Os Incas não participam assim na elaboração "carnal" da sociedade - tão importante na compreensão pano do social - , embora sejam mestres na sua elaboração "formal" por meio da tatuagem e do ritual.

Os mitos do Inca são capazes de expor, em suma, toda uma filosofia da sovinice. Esta, em primeiro lugar, transborda os limites da avareza "material" para formar todo um ethos "introvertido". Na análise, este ethos assume uma natureza ambivalente: destrutiva, mas também estranhamente construtiva, geradora de uma expressão social brilhante - lembremos as belas e grandes aldeias dos canibais incaicos combatidos por Basabo.

O Inca, entre os Kaxinawá e os Shipibo, sistematiza uma série de temas cujo centro é essa alternativa entre doação e retenção, capaz de expressar o conjunto das relações entre uma sociedade e seus outros.

Mas voltemos aos Yaminawa. Se os relatos de Yuwasidawa, o Sovina, fornecem um eixo comum entre a mitologia yaminawa e a tradição "incaica", este paralelo não se estende além do núcleo estritamente "econômico" , isto é, o contencioso pela propriedade das plantas cultivadas e o fogo de cozinha. Yuwasidawa não tem jurisdição sobre assuntos cósmicos, não possui objetos ou artes - ou filhas e irmãs - que interessem aos 
índios; nunca, de outro lado, chega a praticar o canibalismo. É, em outras palavras, um personagem muito menor que o Inca. Para completar seus atributos, devemos recorrer a uma pluralidade de personagens yaminawa. No lado canibal, temos o sinistro Awi Pide, que acaba comendo sua própria carne, depois de devorar esposa e filho neonato; temos um parteiro monstruoso que, como os Incas Kaxinawá, devora a parturiente depois de extrair a criança, ou uma família canibal que reproduz os mesmos costumes antropofágicos daqueles. Do lado "doador", temos os animais.

São os animais - especial mente pássaros - que arrancam os bens do Sovina, como vimos nos mitos correspondentes. Também nos mi tos piro essa luta contra o Sovina fica em geral a cargo de personagens-pássaros ou assimilados a pássaros. Vale a pena destacar que são esses relatos do massacre do Sovina que têm paralelo mais estreito com os equivalentes shipibo e kaxinawá15.

Mas em outras ocasiões os animais mostram sua generosidade com seu próprio patrimônio: os conhecimentos agrícolas com que Kapa, o coatipuru, beneficia os humanos 16 ; os saberes farmacológicos e xamanísticos e as mercadorias manufaturadas obtidas das cobras d'água17. E mais ainda: as artes do parto e os cuidados das crianças do rato ou o savoir-faire sexual do macaco-prego que, com igual direito, salvam os Yaminawa da extinção.

Os Yaminawa - que, diga-se de passagem, não acreditam no bom selvagem - são partidários convictos do bom animal: algo que contrasta com o caráter humano dos vilões da mitologia e - pior - com a retribuição que os humanos dão nos mitos aos seus benfeitores. A generosidade dos animais é um tópico da tradição oral pano: um dos informantes kaxinawá de Capistrano (Abreu 1941:309) elabora mesmo uma lista dos dons devidos aos animais. Mas o mais extraordinário, no caso yaminawa, é que esses animais estejam sempre dispostos a casar - machos ou fêmeas - com os humanos, algo que como vimos nem o melhor dos Incas tinha chegado a fazer.

Vem aqui à tona as referências anteriores à ambígua formulação que os Yaminawa fazem da afinidade. Os termos que se relacionam com ela, ou as próprias regras de casamento, são um terreno de equívocos e reticências. São os animais os únicos que, nos mitos, e sem circunlóquios, se dirigem a quem for preciso como bibiki (prima-esposa); são eles os únicos que conseguem utilizar esses termos "dravidianos" que expressam, simultaneamente, a proximidade e a diferença que deveriam reinar nas relações entre aliados.

Esses animais namoradores são animais-yushi, espíritos. Podemos reconhecer aqui o significado de toda uma vertente "perspectivista" (no sentido dado ao termo por Viveiros de Castro, 1996) da vida yaminawa, 
que tem sua contraparte "totêmica" na multiplicidade de etnônimos que acompanha a extrema fragmentação dos grupos. Os etnônimos yaminawa, cujo conjunto (apesar do tratamento anedótico que os estudiosos em geral Ihe reservam) constitui a classificação mais eficiente na administração do seu sistema social, formam-se, via de regra, a partir de nomes de animais. E compartilham a mesma sina de guerra constante que a mitologia yaminawa atribui ao mundo animal.

\section{Um mundo de cunhados}

$\mathrm{N}$ a elegante conclusão do seu artigo de 1992, Bárbara Keifenheim sintetiza a oposição entre a fil osofia social dos Kaxinawá e a do homem branco que os assedia: "A mensagem 'todos os homens são irmãos' encontrava um mundo onde a expressão mais nobre das relações humanas é a relação de cunhados!"

O texto está prenhe de sugestões. Essa oposição entre os "irmãos" e os "cunhados" ecoa alguns tópicos lévi-straussianos, e ninguém negaria que as culturas do Novo M undo se ocupam muito mais dos cunhados - ou dos afins em geral - que as do Velho. Mas na comparação de Keifenheim deveríamos incluir uma outra torção: o que governa esse mundo dos cunhados não é, necessariamente, um amor universal como o que se espera da fraternidade cristã. Longe disso, se as sociologias ameríndias se ocupam tanto da afinidade é, em boa medida, para sublinhar sua pesada ambivalência. Casar é necessário para fundar uma sociedade, mas é ao mesmo tempo uma condenação a viver perpetuamente "no meio dos outros". A afinidade inicia uma sociedade que teme seu próprio fundamento e tende a postular um ideal endógamo, seja como ideologia seja como utopia. Estou aqui resumindo a filosofia proposta por J oanna Overing (1984) baseada fundamentalmente em uma experiência de campo nas Guianas, onde são comuns os artifícios para converter o afim em consangüíneo, ou o cunhado em irmão. A partir daí, a literatura sobre parentesco sul-americano desenvolve-se ora sublinhando essa produção quotidiana do socius (M cCallum 1998), ora insistindo (Viveiros de Castro 1993) no englobamento da consangüinidade pela afinidade - uma afinidade, porém, cujas fronteiras com a alteridade tout court estão sempre em aberto.

É também notável a extensão na América do Sul de escatologias que desenham um além "incestuoso" em que se prescindiria definitivamente da aliança. $O$ caso mais famoso seria o dos Krahó, na análise de Carneiro da Cunha (1978), ou o dos mesmos Piaroa, na descrição de Overing 
Kaplan (1975). Uma sociedade ideal, purificada das intrusões da afinidade - mas por isso mesmo estagnada, imóvel, morta em suma -, opõe-se à vida real, transbordante de substância, mas aberta sempre ao estranho e portanto assombrada por perturbações que vão do molesto ao atroz. Dessa sociologia pensada às avessas por meio da escatologia participam, em certa medida, os Piro e, sem dúvida, os Yaminawa, que sem meias tintas equacionam os incestuosos a espíritos de mortos.

O comentário de Keifenheim, em suma, não é trivial. A abertura à aliança que, segundo o texto citado, caracterizaria o mundo Kaxinawá, casa, segundo os dados da mesma autora, com um cuidadoso sistema de definição de identidade, que tende a manter a autonomia do grupo ${ }^{18} \mathrm{e}$, em resumo, fomenta decididamente a endogamia. O caso Kaxinawá poderia oferecer uma boa ilustração de como (nos termos de Viveiros de Castro e Fausto 1993) a troca restrita pode servir não tanto à constituição do socius, mas ao fechamento dos nexos endogâmicos locais, dando assim à aliança um valor mais ideológico que sociológico.

$\mathrm{O}$ "modelo" Yaminawa oferece um ângulo muito diferente: uma exogamia intensa está unida a uma visão sombria dessa mesma exogamia. Os próprios grupos que realizam trocas matrimoniais são definidos por conflitos e quebras de grupos anteriores. A presença dos afins dentro do grupo doméstico é dissimulada, um pouco ao modo guianense, mediante a tecnonímia e o uso de categorias consangüinizantes. Os termos "dravidianos" para afins, que são evitados na convivência quotidiana, reaparecem na mitologia, na voz de animais que sempre personificam o afim perfeito. A afinidade aparece, em suma, empurrada para o lado da al teridade, como um subconjunto da predação; não raro os animais que casam com humanos nos mitos acabam sendo tratados como excelentes peças de carne.

Nessa sociovisão yami nawa, em suma, aparecem temas tão disseminados quanto antigos no campo ameríndio; não há razões, como já foi dito, para reduzi-los a resultado do desastroso contato com o mundo dos brancos. A desagregação e o conflito contam também com o prestígio da tradição.

\section{Reforma da identidade, reinvenção da cultura}

Depois de longas digressões, podemos apreciar melhor os modos como a figura do Inca combina com determinados aspectos da organização social dos grupos pano, ou, em outras palavras, explicitar o uso do Inca na construção das sociedades que o põem em jogo na sua mitologia. 
Em primeiro lugar, o complexo do Inca Pano é fiel ao caráter dialético das identidades ameríndias, que têm uma formulação especialmente aguda na cultura pano: o Eu só pode ser conseqüência de um Outro, não há lugar para o monismo. A tribuindo seus signos distintivos e suas tradições mais caras - tatuagem e pintura, especialmente - a um estrangeiro ou a um inimigo, Shipibo e Kaxinawá são simplesmente coerentes com a tradição.

$M$ as as razões desse Inca ganham relevo quando apreciamos as diferenças entre suas versões kaxinawá e shipibo. Os Kaxinawá, segundo as descrições vigentes, baseiam sua organização em uma aliança observada na prática (com a troca restrita) e ideologicamente celebrada (em um dualismo integrador). Para conseguir esse encaixe perfeito é necessário restringir a interação social a uma comunidade endógama, que preenche satisfatoriamente os requisitos da verdadeira humanidade: modos corretos de casamento, de relação entre grupos, de grafismo corporal. Não pode ser maior o contraste com os Yaminawa - para os quais a aliança é essencialmente uma relação trágica com a alteridade - que enfatizam a extroversão e, por isso mesmo, põem entre parênteses o aspecto "interno" de suas práticas de casamento, dissimulando o uso da terminologia dravidiana.

É compreensível assim o papel que os Kaxinawá dão ao Inca: ele é o estrangeiro canibal que se nega à aliança e que, portanto, impõe limites à generosidade exigida pela ideologia kaxinawá do parentesco. Ele mostra a necessidade de marcar limites, e o modo - a tatuagem - de reconhecer os próprios. Para os Yaminawa, o animal generoso ocupa o mesmo lugar do Inca, mas em um argumento de signo oposto: oferece-se em lugar de se guardar, é devorado e não devora quando é a sua vez. Um comportamento inverossímil que consagra a abertura imprudente dos Yaminawa a um mundo onde o homem é lobo para o homem, mas onde homem e lobo costumam andar com peles trocadas.

No caso shipibo, o Inca exerce um papel equivalente, mas diferenciado, ao que desempenha para os Kaxinawá. Sovina ou generoso, ele age como um provedor de bens, um definidor de etnias e um fundador dos signos de identidade que, no entanto, prescinde de uma relação "carnal" com seus apadrinhados. O Inca Shipibo é um fundador sem ser um pai nem sequer um sogro. O Inca Shipibo é um indivíduo, nunca um coletivo como no caso kaxinawá. Não serve assim para catal isar o fechamento endogâmico de um grupo, mas para possibilitar a unidade de um conglomerado que abrange grupos extremamente diversos. "Shipibo" aparece aqui em lugar do binômio Shipibo-Conibo - cada vez menos habitual na literatura - que, por sua vez, inclui os Shetebo e, provavelmente, 
muitos outros velhos grupos do Ucayali, como Remo e Isconahua, e está em processo de assimilar - com a extensão de suas artes gráficas - coletivos tão inimigos quanto os Cashibo. Shipibo é um nome tendencialmente "nacional", que engloba diversas etnias.

Os Incas do Ucayali fazem da negação (relativa) da aliança um caso menor do tema sovinice/doação: o pretendente da filha do Inca vê-se forçado a superar provas difíceis impostas por um sogro ciumento, porém mais ciumento dos seus tesouros que de sua filha. O caso kaxinawá é o inverso: os bens culturais são o prêmio de consolação por uma luta inglória para conseguir a mulher do outro, e a negação da aliança, aqui absoluta, engloba o conjunto.

De novo um contraste agudo com os Yaminawa, que carecem dessa brilhante arte, presente do Inca, que distingue outros Pano. Se os Shipibo tentam afirmar com o casamento distante os laços dentro de uma etnia cujos limites são marcados por signos externos (a pintura e o artesanato), os Yaminawa esforçam-se em marcar a distância entre seus grupos - tão próximos no parentesco e no espaço - , evitando os signos externos de identidade (é a razão de perderem com tanta facilidade sua "cultura" entendida em sentido folclórico) que Ihes forneceriam uma fronteira exterior. Virtualmente, toda a humanidade - inclusive a do pesquisador poderia ser incluída em um conjunto infinito de grupos -nawa.

O Inca - e o Sovina - como imagem do Branco tem sido um argumento tópico nas críticas às leituras literais do Inca Pano. Em comum com outras aplicações da semântica na antropologia, esta tem a fraqueza da racionalização. Se os mitos deviam explicar o Homem Branco, por que então não teriam falado nele diretamente - como tantos grupos indígenas fazem - em lugar de pôr em jogo um personagem que, de modo algum, se confunde com o Branco? Essa cadeira cativa do Homem Branco na mitologia indígena pode muito bem vagar. Devo lembrar que Shipibo e Kaxinawá têm seus próprios mitos sobre o Branco, incluídos no mito do Inca ou claramente diferenciados dele. Em um relato Shipibo (Roe 1988: 129) um Inca oleiro produz o Branco (mal cozido) e o Negro (queimado) antes de criar uma humanidade, a indígena (no ponto). O mito de origem do Branco publicado por D'A ns (1975:336-342) é uma inversão dos mitos incaicos sobre o eixo de análise aqui selecionado, o das atitudes perante a al iança. Kanáibari, um bom Kaxinawá, cede ante o acosso sexual de sua nora, e não pode evitar matá-la com seu pênis desmesurado. Foge então de uma possível vingança do seu filho, instalando-se à beira-rio, e lá se converte em branco, criando as mercadorias que entrega generosamente aos seus ex-conterrâneos. Em lugar de um estrangeiro sovina que se furta 
a qualquer aliança, temos um consangüíneo que é levado a abusar de sua proximidade, mas que compensa o fato com sua generosidade. Os Yaminawa, tão obcecados pela cultura do Branco, não têm mito algum a seu respeito.

Recapitulando, podemos definir três situações aptas para comparação: aquela em que existem mitos a respeito do Inca e a respeito do Branco; aquela em que o mito do Branco é parte do mito do Inca; e aquela em que nem o Inca nem o Branco são protagonistas de mitos. Em termos gerais, trata-se das situações kaxinawá, shipibo e yaminawa. Essa comparação lida com três "etnias" heterogêneas. Sabemos que os Shipibo são um agregado de povos consolidado em função de alguns signos comuns, como a arte e o Inca que a inventou. Sabemos que "Yaminawa" denota alternativamente um nós exclusivo (um grupo assim denominado), um outro excluído (um tipo de índio selvagem e entrópico) e um, digamos, "outro inclusivo" (todos os humanos e os animais, virtualmente classificáveis em uma grade de categorias "nawa"). O termo kaxinawá não tem sido submetido a uma revisão desse tipo, e a literatura especializada concede-Ihe uma identidade discreta - étnica, lingüística e cultural - e dotada de profundidade histórica. Não por acaso são eles os únicos no conjunto aqui tratado que consagraram entre vizinhos e antropólogos o uso de uma autodenominação, Huni Kuin. Resumindo em um quadro parte dos contrastes que foram aqui passados em revista, teríamos o seguinte:

\section{Shipibo-Conibo \\ extensão de um \\ etnônimo particular}

Inca fundador

casamento a longa

distância, mas dentro do

conjunto shipibo-conibo

no mito, o Branco é uma criação imperfeita do Inca

\section{Kaxinawá}

consagração externa de uma autodenominação (Huni Kuin)

Inca canibal/celeste

exogamia de metades, endogamia de aldeia

há um mito de origem do Branco: ele é um Kaxinawá transformado

\section{Yaminawa}

pluralidade de etnônimos "totêmicos"

afins animais

conflitos internos dão

lugar a unidades exogâmicas

não há um mito de origem do Branco: ele é designado pelo termo genérico "nawa” 
O "Inca" ilustra-nos sobre as utilidades de um nome em uma terra organizada por pronomes sociológicos ${ }^{19}$. No caso shipibo (um termo que poderia alargar-se em Shipibo-Conibo-Shetebo-Isconahua-Remo e além...), aglutina mitos e populações em uma nação de tamanho considerável para os padrões amazôni cos atuais ${ }^{20}$. No caso kaxinawá, fixa um outro avesso à troca matrimonial, fazendo da primeira pessoa do plural - Huni Kuin - uma entidade discreta e substancial não questionada pelas trocas externas. No caso yaminawa a "opção nome" manifesta-se em outro âmbito, fazendo dos etnônimos uma rede totêmica (os pseudoclãs nawa) que ocupa o plano mais visível da estrutura social.

Os Shipibo-Conibo, para expressá-lo de outro modo, existem do ponto de vista do Inca; os Yaminawa, do ponto de vista dos outros Pano; os Kaxinawá, do seu próprio ponto de vista, com a ajuda de um espelho inca e um outro Branco.

Nesta visão, o ponto estratégico das estruturas sociais desloca-se do centro - tradições, terminologias ou regras de aliança - para as fronteiras, para a delimitação de identidades; é mais um modo de dizer que elas são produto da história ou mais concretamente dos historiadores ou mitógrafos nativos.

\section{Epílogo: sobre a antiguidade dos modelos}

Ao descrever o modelo kaxinawá, Kensinger deu espaço à especulação histórica. O modelo kaxinawá seria a versão atual mais completa de um model o protopano que outros grupos próximos na geografia e na língua - como os próprios Yaminawa - conservariam em versões mais imperfeitas. As teses de Keifenheim - importantes também na consagração do modelo - evitam um termo arriscado ("protopano"), mas assumem sem pejo suas conseqüências. As categorias sociogênicas do U cayali e dos grupos -nawa são versões progressivamente "borradas" do cânone kaxinawá, cuja potência parece associada a seu maior conservadorismo.

Não é estranho que o exemplo kaxinawa, pelo pioneirismo e volume da sua literatura, seja o referente/antagonista ideal das etnografias sobre os outros "nawa". Essa espécie de boxe com a própria sombra, de que este artigo é um bom exemplo, tende a insistir nas versões mais substancialistas de um modelo que já foi matizado em obras mais recentes (Kensinger 1995; M cC allum 1989b). Isto porque essa substancialização não carece de interesse histórico, sobretudo na medida em que provavelmente tem seguido de perto modelos nativos. 
Nunca é demais, quando se quer fazer inferências sobre o passado, examinar com cuidado as fontes mais antigas de que dispomos. $\mathrm{N}$ o caso kaxinawá estas são, como sabemos, de excelente qualidade. Um texto ditado a Capistrano de Abreu por Borô (A breu 1941:5722-5804; cf. a glosa em Abreu 1938:341-345) guarda algumas especulações kaxinawá sobre o passado, expressas durante o auge mesmo do boom da borracha. O texto narra a dispersão dos Huni Kuin a partir de um primeiro lar, à beira do "rio Zangado" (hönö cinatapa). Lá viveriam dois ancestrais: Harukum (o primeiro) e A pó, concebido depois. Cada um deles gera seu povo "encantando" (damiwani kiaki) uma fruta do mato, kuta (jaci) exebó (uricuri), respectivamente. Harukum tem mulher, muito bonita; A pó não tem e se apaixona pela de Harukum. $\mathrm{Na}$ briga conseqüente, Harukum recrimina a A pó por não ter se casado, tendo muitas mulheres de sua gente, e desejar logo a sua; ameaça, enfim, apoderar-se das mulheres do grupo de A pó. Na luta, Harukum morre, os grupos de ambos os chefes pelejam e se dispersam, subindo uma multiplicidade de rios: o J uruá, o Tarauacá, o Envira, o M uru, o M oronal, o Tawaya, o I buaçú, o Humaitá, o Colombo, o Purus e o Acre (A breu 1938). O relato acaba com um lamento: não tivesse sido essa morte, e ainda viveríamos em aldeias direitas (mae kaya) à beira do rio Zangado.

O interesse desse texto é múltiplo. De um lado, o esquema social que o relato nos apresenta combina el ementos que apareceram em distintos pontos da nossa análise (a endogamia, a recusa da aliança, a fragmentação dos grupos), mas não corresponde a nenhuma das morfologias sociais discutidas nestas páginas. De outro lado, apresenta os Kaxinawá já saudosos de uma ordem primordial, que teria se quebrado em tempos anteriores à chegada dos seringueiros, em um processo interno. Borô contempla a sociedade kaxinawá como o fruto de uma queda, supostamente anterior e al heia aos Brancos.

Em outras palavras, o modelo clássico kaxinawá não é visível no relato - como não é visível, de resto, em toda a coletânea de Capistrano21; essas pendengas entre irmãos ciumentos, se lembram alguma coisa, é antes a belicosa mitologia dos Yaminawa. Poderíamos observar também que a definição da identidade kaxinawá que aparece nos dados de Tastevin contradiz o modelo, por incluir toda a desordenada variedade dos -nawa, em lugar de se destacar dela. O par Harukum-A pó é bastante estranho às sociogonias descritas por Deshayes e Keifenheim, nas quais o começo da sociedade é gerado pelo estabel ecimento da aliança, e os desastres pelo incesto. Harukum e A pó não são cunhados: não está clara a relação entre eles, sabemos apenas que um é mais velho que o outro - 
uma relação significativa entre irmãos. A criação de seus povos não só prescinde da troca matrimonial, mas mesmo da sexual: os heróis formam-nos "encantando" duas espécies de frutas silvestres ${ }^{22}$. A seguir, adotam uma conduta claramente endógama: o pecado de A pó, que põe fim a essa idade de ouro, é aspirar à troca matrimonial, um pecado incompreensível nos termos do modelo kaxinawá, mas que garantiu a A pó uma duradoura fama de vilão. Rafael Girard, que visitou os Kaxinawá nos anos 50 e descreve claramente o modelo tal como agora o conhecemos, cita ainda A pó (1958:228) como protagonista nefando A pó é Lua, o incestuoso. Se Girard não ouviu mal, a moral dos mitos kaxinawá mudou notavelmente em quarenta anos.

Se virarmos a lupa para os Shi pibo, relendo a polêmica sobre os Incas, nos depararemos com dúvidas semelhantes. Assim, o artigo de De Boer e Raymond (1987) indica nada haver na obra, curiosa e profusamente ilustrada, do viajante M arcoy (que singrou o Ucayali pouco antes de 1850) que nos lembre a magnífica cerâmica shipibo atual. De fato, as primeiras amostras plenas dessa arte não surgem antes da segunda metade do século XIX - em coleções como a de Colini (1883; 1884).

Não recordo, acrescento, referências ao Inca Shipibo-Conibo anteriores à do próprio Colini (1884:531). Será que os missionários castelhanos, que trezentos anos antes viam Incas por toda parte, tinham perdido essa sensibilidade? Ou será que os índios escondiam deles uma crença que, segundo a interpretação de Harner (1993), tinha conotações subversivas? E nesse caso, por que a confiaram a um patrão poderoso - e aliado dos missionários - , como Máximo Rodríguez, para que este a transmitisse a Farabee (1922) por volta de 1907? Não nos deparamos com um silêncio documental, mas com um conjunto significativo de silêncios documentais. Não há registro, até quase a virada do século, de Incas Pano ou desse estilo tradicional Shipibo-Conibo; deveremos esperar mais uns decênios para saber dos Kaxinawá "cristalinos" e do seu Inca Canibal.

Em última instância, este exame remete a um tipo de problema cuja exposição mais clássica se deve aos trabal hos de Sahlins (1986). As interpretações do Inca Pano privilegiaram ora o evento - o Inca, uma lembrança de tempos remotos - ora a estrutura - o Inca, uma imagem da alteridade sociológica ou cosmológica. Este artigo levanta uma suspeita sobre a memória e os modelos: ambos podem ser menos antigos e mais intencionais do que aparentam à primeira vista. Não se pretende com isso instituir no seu lugar mitologias ou modelos autênticos ${ }^{23}$, mas identificar uma agência histórica; transpor a discussão para um patamar em que o que interessa não é a falseabilidade dos modelos, mas a sua verificabilidade, isto é, a sua capacidade de tomar corpo e alterar o sistema. Em essência, minha hi pótese se limita a alterar o caráter de um símbolo, de passivo a ativo, do significativo ao performativo: isto é, a resgatar o que o símbolo tem 
de evento. Não me ocupo aqui de povos que lembrem uma figura histórica ou que expressem seja o que for mediante um símbolo, mas de um mito (ligado a um modelo) cujo estabelecimento tem colaborado decisivamente na configuração atual de determinados povos. $O$ aspecto semântico dos símbolos é um tópico mais comum que a sua eficácia histórica; o caso do Inca é um bom exemplo desta última ${ }^{24}$. A historiografia recente sublinha a capacidade de as culturas indígenas reelaborarem suas estruturas em função da experiência histórica; mas, desse modo, ainda subordina as primeiras à segunda, e as distingue dela. As transformações de um conjunto mítico - ou de um modelo social - são fatos históricos, e não só interpretações de fatos históricos; podem estar na base ou à frente de outros fatos, e não somente atrás del es. Isto supõe que eles mudam mais depressa do que gostamos de admitir, pois tomamos a longa duração dos elementos do mito por uma longa duração dos mitos enquanto sistemas. Supõe também que a variabilidade das estruturas constitui sua força, e não o signo de sua falência - um princípio estrutural ista amplamente aceito como enunciado teórico, mas raramente aplicado na descrição.

O que determinou a centralidade do Inca ente os Pano? O boom da borracha, o ingresso massivo dos brancos no universo indígena são conjuros bravos o suficiente, não há como duvidar, para fazer aparecer novos deuses ou heróis fundadores, e para forçar redefinições das fronteiras étnicas. Até aqui, meu argumento equivale ao de Harner (1993), que considera o Inca o centro de um certo messianismo ucayalino. A diferenca está em que para Harner esse mito explicaria a passividade, ao menos temporária, dos índios do Ucayali perante as exações dos brancos: seria mais uma vez uma máquina anti-histórica. Para mim, constam modificações de fato, essenciais e impulsionadas por esse mito, que aliás tem menos a ver com o Branco que com a organização interna do conjunto pano.

Não devemos supor que a história "primitiva" precise de episódios extraordinários para se mover. Pode-se entender melhor as relações entre os modelos pano supondo que é da natureza desses modelos mudar sempre, ao longo de uma história com Incas e Brancos, mas que não tem neles necessariamente seu início ou seu final. 
Oscar Calavia Sáez (Logroño, Espanha 1959), doutor em A ntropologia pela Universidade de São Paulo, realizou pesquisas sobre religião (na Espanha e no Brasil) e etnologia indígena (entre os Yaminawa, Acre), e é atualmente professor do Departamento de Antropologia da UFSC. Publicou Fantasmas Falados: Mito, Escatologia e História no Brasil (1996) e Deus e o Diabo em Terras Católicas (1999).

\section{Notas}

1 Uma boa parte dessa polêmica encontrou lugar nas páginas do mesmo J LAL: assim, a crítica inicial de De Boer e Raymond (1987), a resposta de Lathrap et alii (1987) e a crítica mais particularizada de Erikson (1990). O utros exemplos serão citados ao longo do texto. Uma contribuição paralela, mas afinada com a causa de Lathrap etc., foi a de Harner (1993). Sobre esta última voltarei no final do texto.

2 Um bom exemplo dessa crítica pode ser Roe (1988). Cf., também, McCallum (1989a).

3 Cf. o epílogo de Renard-Casevitz, Saignes e Taylor (1989) e a análise de Erikson (1992:245-246).

4 Nem eles, nem outros povos da área que poderiam ser incluídos sob esse etnônimo. Penso contar com essa "certidão negativa" para os Yaminawa peruanos (Townsley 1988), para os Sharanahua do Purus (Siskind 1973 e Torralba 1986) e para os Yawanawa do rio Gregório (Lúcia Smreczanyi em 1991, comunicação pessoal, e Laura Pérez e Miguel Carid em 1998, comunicação pessoal).

5 Estou me referindo essencialmente aos Yaminawa do rio Acre (Brasil), que pesquisei entre 1991 e 1993 (Calavia Sáez 1995). O que será dito a seu respeito pode em termos gerais se aplicar aos Yaminawa peruanos (Townsley 1988), com algumas exceções que serão focalizadas em seu momento.

6 Incluir na análise contribuições como as referentes aos Marubo exigiria um outro artigo, com um objeto diferente e mais amplo. O mito de shoma wetsa (Melatti 1985; 1989) inverte os termos e o ponto de vista da mitologia "incaica" que aqui nos ocupa: os incas nascem, como outros povos, da implosão de um monstro canibal; são predicados andinos de um sujeito amazônico. 
7 Bardales Rodríguez é um autor conibo que escreve sobre os Incas a pedido do Instituto Lingüístico de Verão. As narrativas que ele arrola são congruentes com as que procedem de outras fontes; a ordem escrita que ele lhes impõe (e talvez seu esquema "trinitário") deve muito, sem dúvida, ao estímulo dos missionários e das suas Escrituras. Seu objetivo de fixar uma tradição pano em torno ao Inca reforça a meu ver a interpretação do Inca Pano que ofereço nas páginas finais deste artigo.

8 A outra versão, atribuída a um Kaxi que residira entre os brancos, tem o interesse de traduzir Inga/N oto Boko em termos católicos, como Deus/N ossa Senhora.

9 Exposição de arte organizada na Universidade Federal de Santa Catarina (UFSC) durante o Encontro Pano, novembro de 1998.

10 Yuwasi dawa é uma exceção só na aparência: dos quatro relatos a seu respeito - recol hidos de um único informante — os dois últimos são episódios particulares, em que o protagonismo passa do Sovina para um dos seus oponentes animais; os dois primeiros são relatos quase idênticos, em que o personagem muda de Sovina para bruxo. Longe de alinhavar uma "saga" a partir de mitos diversos, o narrador está fragmentando um único relato.

11 "Dakota-iroquês" foi um rótulo aplicado ao conjunto dos sistemas de "duas seções" antes que a consideração de outros critérios (cálculo de cruzamento, presença/ausência de termos específicos para afins efetivos etc.) levasse a diferenciar dentro daquele conjunto o sistema elementar dravidiano e os sistemas complexos de tipo "dakota-iroquês". Não disponho de dados conclusivos sobre o parentesco yaminawa, mas creio que o uso do termo "dakota" se justifica pelo modo negativo como os Yaminawa formulam as normas de casamento, pela sua freqüente alusão a supostos sibs de resto invisíveis, e pelo uso de uma terminologia especial para os parentes por aliança, dados que contrastam nitidamente com a versão dravidiana (sistema de duas seções associado ao casamento de primos cruzados) que se pode auferir de outros informes paralelos e não menos yaminawa.

12 Essa harmonia entre ideologia e função é praticamente única na A mazônia, onde aparecem por toda parte sistemas dualistas sem metades exogâmicas ou metades exogâmicas sem sistema dualista (cf. Viveiros de Castro 1993).

${ }^{13}$ Esse casamento a longa distância que não chega, no entanto, a ser um casamento "fora" exige o conhecimento de longas genealogias; se, de um lado, esse recurso lembra a hipótese dos "clãs" yaminawa, de outro, contrasta com sua tendência a cortar elos de parentesco que escapem à comunidade de residência. Devo advertir que meus dados a respeito são secundários: derivam de Keifenheim (1992), de umas observações de Girard (1958) e de uma curtíssima experiência pessoal no Madre de Dios peruano.

${ }^{14}$ Aliás, temos aqui mais uma analogia com missionários, antropólogos ou brancos em geral: nada impede que o Branco seja extremamente generoso com 
ferramentas, livros, motores para canoa, sua própria vida ou as verbas do governo; mas ele jamais é doador de mulheres, não participa da elaboração social.

${ }^{15}$ Caberia aqui um argumento em favor de uma derivação dos mitos shipibo sobre o Inca de outros mitos anteriores, semelhantes aos dos yaminawa sobre o Sovina. J unto ao Inca Sovina (Yoaxico) temos de fato dois Incas doadores: um deles é o Chane Inca, nome de um dos pássaros que participam comumente da matança do Sovina na mitologia de vários grupos; o outro apresenta uma negritude inexplicada que parece remeter também à coloração dos animais no sangue do Sovina.

${ }^{16}$ Que inverte, aliás, o ubíquo episódio do genro que o Inca tenta queimar no roçado. No caso de Kapa, o cunhado efetivamente se queima por não ouvir os conselhos do afim, que finalmente consegue ressuscitá-lo com seus poderes mágicos.

17 Em outro mito (M22 da minha coleção) as cobras d'água presenteiam um parente humano com machados, tecidos, espingardas e cachorros que elas possuem, e que segundo uma das versões do mito elas teriam conseguido nos seus assal tos aos batelões dos brancos. Vale a pena indicar que esse relato ocupa o lugar que muitos outros grupos indígenas dedicam à mitificação do homem branco.

18 A té o ponto em que, como propõe Deshayes (1992), os conflitos internos dos grupos e os rompimentos decorrentes deles - menos freqüentes do que entre os Yaminawa, mas não por isso negligenciáveis - seriam úteis para preservar os grupos do monadismo.

19 Sobre os pronomes, cf. Viveiros de Castro (1996); a partir dele pode ser sugestivo considerar o valor "pronominal" das categorias de identidade pano sistematizadas por Keifenheim; essa definição abre por contraste a possibilidade de uma sociologia dos etnônimos, que estou ensaiando em outro trabalho.

20 Sobre os Shipibo-Conibo como "nação", cf. Lévy (1991).

${ }^{21}$ É claro que pode tratar-se de uma lacuna, considerável: o mesmo Capistrano fazia reservas quanto à erudição de seus jovens informantes. Mas vale a pena compará-la com o trabalho do etnólogo-turista Rafael Girard, que quase cinqüenta anos depois, após um breve contato com índios Kaxinawá - mediado por Kensinger e Cromack, que realizavam trabalho de campo naquela época - , expõe esse modelo completo em primeiro plano. O modelo tinha ganho, no mínimo, visibilidade.

22 O que lembra, sem dúvida, aquela noção de "povos autóctones" (LéviStrauss 1985) em que a origem imediata da terra entra em conflito com as evidências da reprodução sexuada.

23 É preciso evitar a tentação de trocar os signos habituais, fazendo de shipibo e kaxinawá etnias "emergentes" e dos Yaminawa primitivos ingênuos. Cabe advertir que a "desordem" destes não carece de sistema, e que a "dakotização" dos Yaminawa acrianos (e talvez a fragmentação da sua mitologia) supõe um afas- 
tamento do padrão dos -nawa peruanos e do que pode ter sido norma no próprio grupo em época recente.

24 Durante um breve trabalho de campo no rio Gregório, em 1998, pude comprovar que o Inca, absolutamente ausente na mitologia "tradicional" yawanawá, aparece eventual mente no discurso dos jovens líderes que estão conduzindo um processo de estabilização e consolidação do grupo com um ideário tradicionalista. As acepções amazônicas do Inca, afinal, não apresentam solução de continuidade com as ideologias indianistas que se sucedem desde Garcilaso.

\section{Referências bibliográficas}

ABREU, J oão Capistrano de. 1938. Os Caxinauás. Ensaios e Estudos, 3. Rio de J aneiro: Edição da Sociedade Capistrano de Abreu. pp. 275-347. 1941 [1914]. Rã-txa hu-ni-ku-i: Grammática, Textos e Vocabulário Caxinauás. Rio de J aneiro: Edição da Sociedade Capistrano de Abreu.

ALVAREZ, Ricardo. 1972. Les Structures Sociales, Politiques et Economiques des Piro. Thése Doc. III Cycle EPHE, Sorbonne.

BARDALES RODRÍGUEZ, César. 1979. “Quimisha Incabo Ini Yoia - Leyendas de los Shipibo-Conibo sobre los Tres Incas". Comunidades y Culturas Peruanas, 12 , M inisterio de Educación - ILV, Peru.

CALAVIA SÁEZ, Oscar. 1995. O N ome e o Tempo dos Yaminawa. Etnologia e História dos Yaminawa do Alto Rio Acre. Tese de Doutorado em Antropologia, DA/FFLCH/USP.

CARNEIRO DA CUNHA, Manuela. 1978. Os M ortos e os Outros: Uma Análise do Sistema Funerário e da Noção de Pessoa entre os Índios Krahó. São Paulo: Hucitec.
COLINI, Giuseppe. 1883. “Collezione Etnologica degli Indigeni dell'Alto Amazzoni". Bolletino della Societá Geográfica Italiana, VIII:287-310, 353-383.

. 1884. “Gli Indiani dell'Alto Amazzoni". Bolletino della Societá Geográfica I taliana, IX:528-555, 708-717. D'ANS, A ndré M arcel. 1975. La Verdadera Biblia de los Cashinahua. Azul Lima: Ed. Mosca.

DE BOER, Warren e RAYMOND, J. Scott. 1987. “Roots Revisited: The Origins of the Shipibo Art Style". J ournal of Latin American Lore, XIII(1):115-132.

DESHAYES, Patrick. 1992. "Paroles Chassées. Chamanisme et Chefferie chez les Kashinawa". J SA, LXXVIII-II: 95-106.

e KEIFENHEIM B. 1982. La Conception de l'Autre chez les Kashinawa. Tese de Doutorado, Université Paris VII.

ERIKSON, Philippe. 1990. "How Crude is Mayoruna Pottery?". J ournal of Latin American Lore, 16(1):47-68. . 1992. "A Etno-História Pano". In: M. Carneiro da Cunha (org.), His- 
tória dos Índios no Brasil. São Paulo: Companhia das Letras. pp. 231-252. FARABEE, William C. 1922. "The Indian Tribes of Eastern Peru". Papers of the Peabody M useum in Archeology and Ethnology, 10. Harvard University.

GIRARD, Rafael. 1958. Indios Selváticos de la Amazonia Peruana. M éxico: Libromex Editores.

HASSEL, J orge von. 1906. “Las Tribus Salvajes de la Región Amazónica del Perú". Boletín de la Sociedad Geográfica de Lima, XVII:27-73.

HARNER, M ichael. 1993. "Waiting for Inca God: Culture, Myth, and History". In: W. H. Kracke (ed.), Leadership in Lowland South America. South American Indian Studies, 1 Bennington College. pp. 53-60.

HORNBORG, Alf. 1988. Dualism and Hierarchy in Lowland South America. Trajectories of Indigenous Social Organization. Stockholm: Almquist $\&$ Wiksell.

KEIFENHEIM, Bárbara. 1992. “Identité et Alterité chez les Indiens Pano". J ournal de la Société des Americanistes, LXXVIII-II:79-93.

KENSINGER, Kenneth. 1984. “Studying the Cashinahua". In: J. P. Dwyer (ed.), The Cashinahua of Eastern Peru. Providence, R. I. Haffenreffer Museum of Anthropology. pp. 9-85. . 1991. Panoan Kinship Terminology and Social Organization: Dravidian or Kariera, or Something Else? Trabalho apresentado no simpósio Classic Panoan Topics in Light of Recent Research, 47th International Congress of Americanists, New Orleans.

. 1995. How Real People Ought to Live. The Cashinahua of Eastern Peru. Prospect Heights: Waveland Press. LAGROU, Elsje. 1998. Caminhos, Duplos e Corpos. Tese de Doutorado em Antropologia, DA/FFLCH/USP.
LATHRAP, Donald, GEBHART-SAYER, Angelika e MESTER, Ann. 1985. "The Roots of the Shipibo Art Style: Three Waves on Imiriacocha or there were Incas before the Incas". J ournal of Latin American Lore, XI(1): 31-120.

LATHRAP, D. et alii. 1987. "Further Discussion of the Roots of the Shipibo Art Style: A Rejoinder to DeBoer and Raymond". J ournal of Latin American Lore, XIII(2):225-272.

LÉVI-STRAUSS, Claude. 1985 [1958]. “A Estrutura dos Mitos". In: Antropologia Estrutural. Rio de J aneiro: Tempo Brasileiro. pp. 237-265.

LÉVY, Daniel. 1991. The N otion of a Nation: The Shipibo-C onibo. Trabalho apresentado no simpósio Classic Panoan Topics in Light of Recent Research, 47th International Congress of Americanists, New Orleans.

MCCALLUM, Cecilia. 1989a. Our Own Incas. The Cashinahua in History. datilo.

. 1989b. Gender, Personhood and Social Organization amongst the Cashinahua of Western A mazonia. Doctoral Dissertation, London School of Economics. .1996. "Morte e Pessoa entre os Kaxinawá". Mana, 29(2):49-84. . 1998. “Alteridade e Sociabilidade Kaxinauá: Perspectivas de uma A ntropologia da Vida Diária". Revista Brasileira de Ciências Sociais, 13(38):127-136.

MELATTI, J ulio Cezar. 1985. “A Origem dos Brancos no Mito de Shoma Wetsa". Anuário Antropológico, 84:109-173. . 1989. "Shoma Wetsa: A História de um M ito". Ciência Hoje, IX(53):56-61.

OVERING KAPLAN, J oanna. 1975. The Piaroa, a People of the Orinoco Basin: A Study in Kinship and Marriage. Oxford: Clarendon Press. . 1984. "Dualism as Expression of Difference and Danger: Marriage 
Exchange and Reciprocity among Thye Piaroa of Venezuela". In: K. Kensinger (org.), M arriage Practices in Lowland South American Societies. Urbana: University of Illinois Press. pp. 127-155.

RENARD-CASEVITZ, F. M., SAIGNES, T. e TAYLOR, A. C. 1989. Al Este de los Andes: Ensayo sobre las Relaciones entre Sociedades Andinas y A mazónicas, Siglos XIV-XVII . Abya-Yala: Quito.

ROE, Peter G. 1982. The Cosmic Zygote: Cosmology in the Amazon Basin. New J ersey: Rutgers University Press. . 1988. "The J osho Nahuambo Are Wet and Undercooked: Shipibo Views of the Whiteman and the Incas in Myth, Legend, and History". In: J. Hill (org.), Rethinking History and $M$ yth: Indigenous South American Perspectives on the Past. Urbana: University of Illinois Press. pp. 106-135.

SAHLINS, Marshall. 1986. Islands of History. Chicago: The University of Chicago Press.

SISKIND, J anet. 1973. To Hunt in the Morning. London: Oxford University Press.

TASTEVIN, Constantin. 1925. "Le Fleuve Murú". La Geographie, XLIII:403422 e XLIV:14-35.

TORRALBA, Adolfo. 1986. Sharanahua. Madrid-Lima: Secretariado de Misiones Dominicanas.

TOWNSLEY,Graham. 1988. Ideas of Order and Patterns of Change in Yaminahua Society. Ph.D. Thesis, University of Cambridge.

VIVEIROS DE CASTRO, Eduardo. 1993. "Alguns A spectos da A finidade no Dravidianato Amazônico". In: E. Viveiros de Castro e M. Carneiro da Cunha (orgs.), Amazônia: Etnologia e História Indígena. São Paulo: NHII-USP-FAPESP. pp. 149-210.
. 1996. “Os Pronomes Cosmológicos e o Perspectivismo Ameríndio". Mana, 2(2):115-144. e FAUSTO, Carlos. 1993. “La Puissance et I'Acte. La Parenté dans les Basses Terres d'Amérique du Sud". L'Homme, XXXIII(126-128):141-170. 


\section{Resumo}

Os mitos relativos ao Inca recolhidos na Amazônia entre vários grupos de língua pano têm sido entendidos como memórias de um passado remoto regido por uma aristocracia quechua ou como expressão de uma estrutura identitária ou cosmológica em que o Inca significaria o Branco ou uma alteridade celestial. Tais interpretações, apesar de seu valor heurístico, limitam nossa compreensão dos aspectos estruturais e históricos do Inca Pano. Propõe-se aqui entender o Inca também como um símbolo eficiente, vinculado a modelos sociológicos e/ou artísticos de alto val or distintivo: povos como os Shipibo-Conibo e os Kaxinawá cristalizam em torno dessa figura uma tradição que os destaca do conjunto dos grupos nawa vizinhos.

\section{Abstract}

The Amazonian myths collected among certain Panoan-speaking peoples which make reference to the Inca figure have generally been subject to one of two interpretations. They are either seen to recall a remote past in which these peoples may have been ruled by Quechua aristocrats or they are seen to be structural aspects of identity or cosmology, in which the Inca would be representative of the White man or of some celestial al terity. These interpretations, in spite of their heuristic value, serve to limit our understanding of structural and historical aspects of the Pano Inca. This article proposes that we also try to understand the Pano Inca as an effective symbol, related to social and/or artistic models with their own distinctive values: people such as the Shipibo-Conibo and the Kaxinawa have shaped around this figure a tradition which sets them apart from the neighbouring $\mathrm{N}$ awa groups. 